\title{
Analysis on Financial Management of E-commerce Enterprise Yiming Li
}

North China Electric Power University, No.2 Beinong Road, Changping District, Beijing, China 18811357011@163.com

\author{
Keywords:E-commerce, Financial management, E-commerce enterprises
}

\begin{abstract}
With the revolution of information technology and the innovation business model, E-commerce has penetrated into many fields. E-commerce enterprises have a big difference from traditional enterprises, so the focus in the aspect of financial management also differs.After analyzing the e-commerce enterprises' characteristics on financing,generation and transmission of financial information and transaction costs,the paper points out some existing problems and gives some relevant countermeasures.Finally, the paper stress that the research on e-commerce enterprises' financial management is critical for the sustainable development of them.
\end{abstract}

\section{Introduction}

E-commerce usually refers to a new business model, under the open network environment and based on browser or server applications, and which is in a wide range of commercial trade activities around the world. Under this model, through the internet ,the buyers and sellers can do all kinds of commercial activities not face to face, consumers and merchants can carry out trading activity, financial activity, relatively comprehensive service activity and so on. In brief, e-commerce is commercial activity inseparable from the platform of the Internet. E-commerce has found its place in many areas such as tourism, medicine, learning and shopping. The Internet provides a lot of new possibilities and development space for the improvement of financial management therefore it is necessary to research on the financial management of e-commerce enterprises.

\section{The Analysis of Financial Management Characteristics of E-commerce Enterprises}

Financing Characteristics of E-commerceEnterprises. High financing risk, huge financing amount and single financing channel seem to be the obvious features existing in the financing process ofe-commerce enterprise.

Generally, the products or services provided by e-commerce enterprises have innovative to some extent, which are uncertain to be accepted by consumers. The operation is also full of hazard because of copy and imitation. For instant, soon after a kind of software providing car wash service appears on the market, lots of software with similar functions quickly sprang up. The enterprise faces the risk of being eliminated if its technology and business strategy are not at the forefront of this area.

The entrepreneur team of E-commerce enterprise is sensitive to the market or masters new technology, however, the lack of found leads to rely deeply on the early financing. What the e-commerce enterprise in the initial needs most is to occupy the market share. That demands cultivating consumers' spending habits and large amount of money for marketing [1]. In addition, the e-commerce enterprises usually condensetheir profit margins in order to stand out from the competition, for example, providing software and service free of chargewhich results in enterprises running in the red. In order to maintain their advancement, e-commerce enterprises also need to spend more manpower and money on research and development. These all require enterprise getting a lot of money to support.

Generally, the risk aversion degree of banks and financial institutions is high. They value a short-term profit of the enterprise. But it is difficult for the outside investors to grasp the enterprise's prospect. Venture capitalists tend to like the enterprise of high risk high reward. They care about the long-term development of the enterprise and the future earnings, so venture capital becomes the 
main financing channel of e-commerce enterprises.

The Characteristics of Generation and Transmission ofFinancial Information. With the promotion of accounting computerization, traditional enterprise accounting treatment efficiency has been greatly improved, but its promptness and shareability of financial information generated and passed still nowhere near the E-commerce enterprise.

In the E-commerce enterprise business processes, after the occurrence of business, electronic documents and settlement go for automated processing, business data is on-line inputted and formed the original documents [2]. The original business data is rapidly transferred and shared between the enterprise business department and accounting department through the internet. And then business data is handled by accounting software automatically in a timely manner, converting business information into the accounting information in real time. The whole process of enterprise financial management is dynamic and timely, making the whole financial information generation and transmission efficiency greatly increased.

Due to the application of financial software and characteristics of E-commerce, financial staffs increasingly need to make analysis and decision rather than the basic financial accounting work.

The Characteristics of E-commerce Enterprise Transaction Cost. Dahlman (1979) categorize the contents of trading activity, considering transaction cost contains: information researching cost, consultation and decision-making cost, contrast cost, monitoring cost, executory cost and conversion cost.Briefly, the so-called transaction cost is the cost of information seeking, conditions for negotiations andtransaction implementation along with the trading behavior.

Before trading in the traditional way, the sellers need to go through various means to show the information of their products or services, including staff promotion, advertising, trading show promotion and others. The buyers also need to spend a lot of time to search for information in order to better meet their needs. Under the E-commerce environment, network provides a platform for E-commerce enterprise to show their product or service. Consumers can easily through some web search engines to get information putted [3]. Due to the search engine can be restricted to certain conditions, consumers can save a lot of screen time.

In the process of trading, both Trading parties can negotiate through the network and achieve electronic contract, including the responsibility both sides must fulfill, the mode of transportation, and the delivery term. Signing a contract online can reduce the travel expenses and other related fees on both sides, and improve the efficiency of the contract as well.

After the completion of the transaction, companies also need to solve the after-sales problems for customers. Generally, in order to improve customers' satisfaction, companies need to invest more in customer service. The spending in the traditional enterprise is also inevitable. Under the traditional way, customers' problems in the use of the product may need to be solved at the physical store. But under the E-commerce environment, often these issues can be solved through communication with the customer service online efficiently.

\section{The Finance Management Problems of E-commerce Enterprise and Suggestion for That}

Improving the Awareness and the Ability of Risk Management.The characteristics of E-commerce business invent its financing difficulties. There is a long way to go to get out of the dilemma. In addition to rely on the government's policy to optimize financing environment, enterprises also need to make efforts to enhance the risk management consciousness and ability.

Enterprise must first establish an effective risk early warning mechanism to lay a foundation for successfully manage and control financial risk. E-commerce enterprise risk early warning system should meet the functional requirements including information collection, information identification, risking assessment, pre-control and warning [4]. Enterprises need to develop and seek high professional managers familiar with themselves and the external situation in the industry, and then establish and improve the risk early warning system in combination with relevant experts' advice. Moreover, Enterprise can effectively prevent risk by strengthening the internal control. By means of perfecting the management system and internal control system, enterprise's economic activities can 
be under the supervision of the internal and external that makes enterprise operations more transparent, financial information more real.

Strong awareness and ability of risk management contribute to the efficiency of enterprise operations, evenly may extend the management life cycle of enterprise. These enhance the investor's investment confidence and intangibly increase competiveness of the enterprise in the process of capital resource competition.

Improving the Quality of Financial Staffs. As it mentioned above, the fundamental accounting work doesn't need to be done manually, financial staff need more to join the management and decision-making. Due to the network financial information processing and transmission is done and completed by computers, the accountants enterprises needed are people who can master and operate the computer. At present our country enterprises financial staffs' education level is generally low, structure of knowledge is comparing single and the financial staffs who are good at computer is small.

First, enterprises should be strictly in the process of recruitment and clear their recruitment requirements hierarchy characteristic of financial staffs. Experienced senior financial manager can help enterprises better carry out tax planning, capital operation, budget management, etc. For the general accounting staffs, it is a very good thing for the company if they can grasp skilled computer operation. In addition, Enterprises should also organize regular staff training work. Financial work environment and accounting standards are also in constant change and development, hence the financial staffs also need to keep learning to adapt to these change.

All in all, improving the whole quality of financial staffs is critical.

Setting up the Correct Cost Management Consciousness. Although compared with traditional enterprises,e-commerce enterprises save the transaction cost in many aspects, they make their profit margins less and competitive advantage in the industry weak due to be neglectful of cost management.

Most of e-commerce enterprises have not formed a set of effective cost management system of their own and their definition of the cost is too narrow that they only take the cost actually happening into consideration. Such as an enterprise dedicated to lot retail can control cost by other means except reducing prime cost simply through negotiations with suppliers. Enterprises can improve customers' satisfaction and boast sales through strengthen service levels, and then form economies of scale. Besides it, enterprises can encourage employees to improve the cost consciousness and make them be willing to use the least resources to complete their task by a moderate amount of rewards and punishments. Certainly, reasonable planning and construction of logistics system also can save cost.

Cost management is not just to think about how to spend lessbut more should consider how to spend money reasonably. Enterprises must set up the correct cost management consciousness and formulate reasonable cost management goals. The way of long-term development is that enterprises can use appropriate cost management method combined with actual situation.

\section{Conclusion}

In the fierce market competition, if e-commerce enterprises want to success, in addition to rely on daily operation and management, needing to pay more attention to financial management. E-commerce enterprises should clear its own characteristics, set up the correct financial management consciousness and develop financial management methodshaving a definite object in view. Only in this way can enterprises in the fierce competitive lines stand out and access to better sustainable development. 


\section{References}

[1] H.M .Li.E-commerce Enterprises Financing Problems and Countermeasures [J]. Economic exploration, 2015:51.

[2] Meharia, Priyanka. E-Commerce and Taxation: Past, Present and Future [J]. IUP Journal of Accounting Research and AuditPractices, 2012(4)

[3]R.f.Li. Analysis on Problems and Countermeasures of E-commerceEnterprises'cost Management [J].Electronic Text, 2013:185-186.

[4]G.H.Lv.Construction of Early Warning System ofEnterprise Electronic Commerce Risk [J].Journal of Hunan Institute of Humanities, Science and Technology, 2012:27-30. 